OPEN ACCESS

Edited by:

Feng Gao,

Tianjin University, China

Reviewed by:

Martin Hagemann,

University of Rostock, Germany

Elke Dittmann,

Universität Potsdam, Germany

*Correspondence:

Yuuhiko Tanabe

tanabe.yuuhiko.fn@u.tsukuba.ac.jp

Specialty section: This article was submitted to Evolutionary and Genomic Microbiology,

a section of the journal Frontiers in Microbiology

Received: 27 March 2018 Accepted: 14 May 2018

Published: 05 June 2018

Citation:

Tanabe Y, Hodoki Y, Sano T, Tada K and Watanabe MM (2018) Adaptation

of the Freshwater Bloom-Forming

Cyanobacterium Microcystis

aeruginosa to Brackish Water Is Driven by Recent Horizontal Transfer of Sucrose Genes.

Front. Microbiol. 9:1150. doi: 10.3389/fmicb.2018.01150

\section{Adaptation of the Freshwater Bloom-Forming Cyanobacterium Microcystis aeruginosa to Brackish Water Is Driven by Recent Horizontal Transfer of Sucrose Genes}

\author{
Yuuhiko Tanabe ${ }^{1 *}$, Yoshikuni Hodoki ${ }^{2}$, Tomoharu Sano ${ }^{3}$, Kiyoshi Tada ${ }^{1}$ and \\ Makoto M. Watanabe ${ }^{1}$
}

${ }^{1}$ Algae Biomass and Energy System R\&D Center, University of Tsukuba, Tsukuba, Japan, ${ }^{2}$ Center for Ecological Research, Kyoto University, Kyoto, Japan, ${ }^{3}$ Center for Environmental Measurement and Analysis, National Institute for Environmental Studies, Tsukuba, Japan

Microcystis aeruginosa is a bloom-forming cyanobacterium found in eutrophic water bodies worldwide. M. aeruginosa blooms usually occur in freshwater; however, they have also been reported to occur in brackish water. Because $M$. aeruginosa often produces the cyanotoxin microcystin, they are a major concern to public health and environment. Despite this, the ecology, genomic basis, and evolutionary process underlying the $M$. aeruginosa bloom invasion from fresh to brackish water have been poorly investigated. Hence, in the present study, we have sequenced and characterized genomes of two newly discovered salt-tolerant $M$. aeruginosa strains obtained from Japanese brackish water lakes (Lakes Shinji and Tofutsu). Both genomes contain a set of genes for the synthesis of osmolyte sucrose (sppA, spsA, and susA), hitherto identified in only one strain (PCC 7806) of $M$. aeruginosa. Chemical and gene expression analyses confirmed sucrose accumulation induced by salt. A comprehensive genetic survey of $>200$ strains indicated that sucrose genes are extremely rare in $M$. aeruginosa. Most surprisingly, comparative genome analyses of the three strains indicated extremely low genetic diversity in the sucrose genes compared with other core genome genes, suggesting very recent acquisitions via horizontal transfer. Invasion of $M$. aeruginosa blooms into brackish water may be a recent event triggered by anthropogenic eutrophication of brackish water.

Keywords: Microcystis, bloom, salt tolerance, sucrose, genomics, brackish water, horizontal gene trasnfer, ecotype

\section{INTRODUCTION}

Water blooms formed by phytoplankton species are often observed in eutrophic bodies of water. Among blooming phytoplankton, Microcystis aeruginosa is the most common and widespread cyanobacterial species found in freshwater environments extending from tropical to subfrigid zones (Harke et al., 2016). M. aeruginosa blooms cause several environmental problems, including bad odor and bottom-layer hypoxia; however, the problem of greatest concern is the production of hepatotoxic cyanotoxins called microcystins (Harke et al., 2016). Cases of human poisoning 
(Jochimsen et al., 1998), livestock intoxication (Beasley et al., 1989), and mass mortality of wildlife (Miller et al., 2010a) caused by microcystin contamination have been sporadically reported. Moreover, recent studies suggest increasing frequency of toxic (microcystin-producing) $M$. aeruginosa blooms in response to climate change (Paerl and Otten, 2013).

Most $M$. aeruginosa strains are not well adapted to salinated water (Otsuka et al., 1999; Tonk et al., 2007), so M. aeruginosa blooms occur predominantly in freshwater environments. Although less common, $M$. aeruginosa blooms have also been reported in brackish water such as lagoons and estuaries (Preece et al., 2017). Some of these cases can be explained by movement from a freshwater origin (e.g., blooms drifting down a river from a freshwater reservoir to a coastal area) rather than local growth (Miller et al., 2010a). However, the possibility of $M$. aeruginosa blooms in brackish water arising due to genetic acquisition of salt tolerance has not been explicitly studied.

In bacteria, salt tolerance is achieved by a complex mechanism including extracellular transport of various inorganic ions (e.g., $\mathrm{Na}^{+}, \mathrm{K}^{+}, \mathrm{Ca}^{2+}$, and $\mathrm{Cl}^{-}$). However, the hallmark feature of salt-tolerant bacterial cells is the accumulation of low molecular weight osmoprotectant molecules called compatible solutes inside the cells (Le Rudulier et al., 1984). The accumulation of compatible solute decreases the water potential inside the cells so that cells can retain osmotic pressure and avoid dehydration. In addition, physiochemical theory suggests that macromolecules can avoid denaturation under high salinity owing to transformation in water structure induced by compatible solutes (Roberts, 2005). In cyanobacteria, low levels of salt tolerance (up to $0.6 \mathrm{M} \mathrm{NaCl}$ ) can be achieved by synthesizing and accumulating sugar compatible solutes, sucrose or trehalose, whereas high levels of salt tolerance can be achieved by glucosylglycerol or gluosylglycerate (up to 1.7 $\mathrm{M} \mathrm{NaCl}$ ) and glycine betaine or glutamate betaine (up to $3.0 \mathrm{M} \mathrm{NaCl}$ ) (Hagemann, 2011). To date, only one strain of M. aeruginosa, M. aeruginosa PCC 7806, which was isolated from brackish water in the Netherlands, has been shown to possess genes for compatible solute (Sandrini et al., 2015). PCC 7806 has a low level of salt tolerance [up to $10 \mathrm{~g} \mathrm{l}^{-1}$ $(\approx 0.17 \mathrm{M})$ of $\mathrm{NaCl}$ ] (Tonk et al., 2007), and like other lower salt-tolerant cyanobacterial species, it accumulates a sucrose as a compatible solute (Kolman and Salerno, 2016). Three genes have been identified as being responsible for sucrose synthesis in PCC 7806: sppA, spsA, and susA (Frangeul et al., 2008). Further, molecular and biochemical analyses also suggested that these gene products are responsible for sucrose synthesis and accumulation in PCC 7806 (Kolman et al., 2012; Kolman and Salerno, 2016). However, owing to the lack of genetic information regarding the salt tolerance of $M$. aeruginosa, apart from PCC 7806, whether other salt-tolerant $M$. aeruginosa strains harbor sucrose genes or other genes for salt tolerance remains unknown. The availability of sucrose genes from other strains allows us to infer the tempo and mode of sucrose gene acquisition in $M$. aeruginosa. Such information would provide us with an insight into the bloom occurrence of $M$. aeruginosa in brackish water.
To address these issues, we have characterized two newly discovered salt-tolerant $M$. aeruginosa strains ( $\mathrm{Sj}$ and NIES1211) obtained from two different Japanese lakes using whole genome sequencing, growth experiments, and chemical and gene expression analyses. We also demonstrated that salttolerant genotypes are extremely rare, whereas their occurrence is widespread at least in Japan. Most surprisingly, comparative genome analyses strongly suggest that the sucrose genes have been acquired by multiple recent horizontal gene transfers (HGT). Our data provide insight into how HGT of genes with an adaptive trait (production of an osmoprotectant) can impact cyanobacterial ecology in aquatic environments.

\section{MATERIALS AND METHODS}

\section{Strains}

Microcystis aeruginosa strain $\mathrm{Sj}$ was isolated from a bloom sample at Shinji-cho, Lake Shinji (Figure 1, Supplementary Table S1), using a micropipetting method. The strain will be deposited at the Microbial Culture Collection of the National Institute for Environmental Studies (MCC-NIES, Tsukuba, Japan). Strains NIES-843 and NIES-1211 were obtained from MCC-NIES.

\section{Growth Experiments}

A late exponential culture of $M$. aeruginosa in salt-free MA medium (Kasai et al., 2004) was used as an inoculum. Briefly, $500 \mu \mathrm{l}$ of $M$. aeruginosa cell suspension was inoculated into

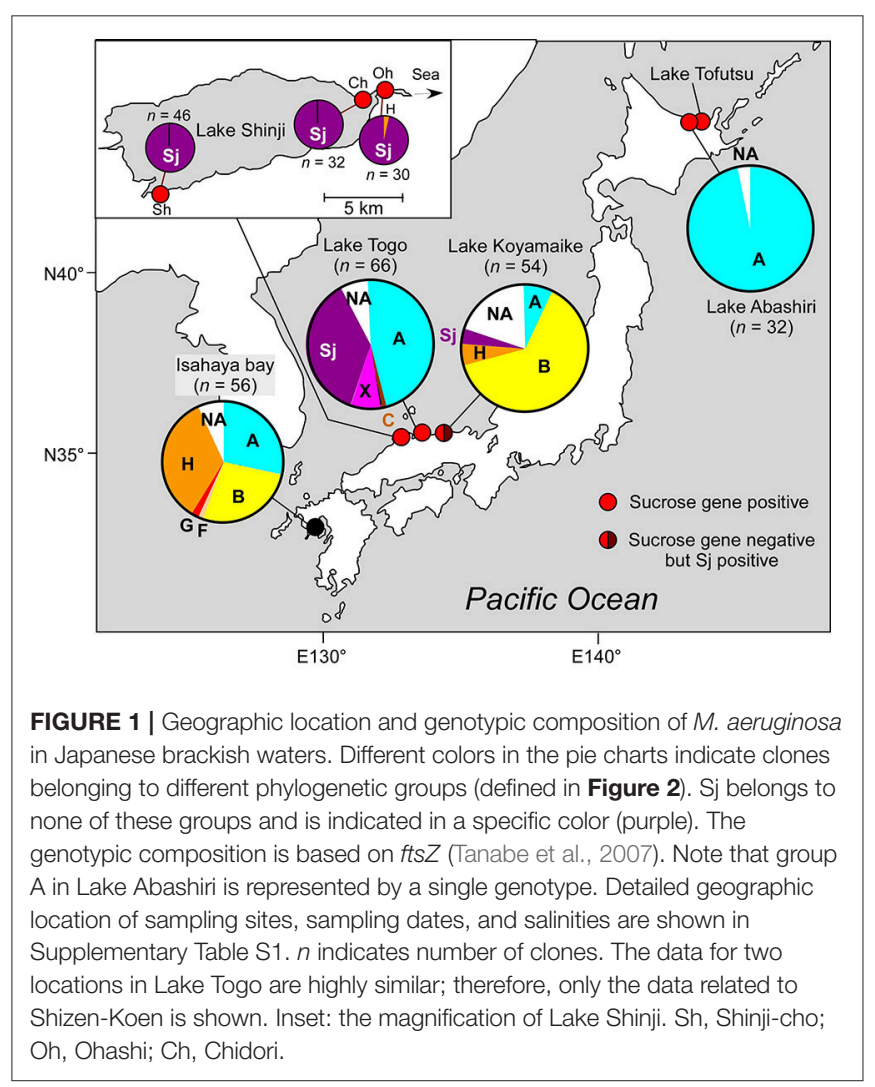


$10 \mathrm{ml}$ of MA with different final concentrations of $\mathrm{NaCl}(0$, $2.5,5,7.5,10$, and $\left.12.5 \mathrm{~g} \mathrm{l}^{-1}\right)$. Samples were grown in-20 ml screw cap test tubes in an incubation chamber at $23^{\circ} \mathrm{C}$ under a $12 \mathrm{~h}$ light (12-14 $\mu \mathrm{mol}$ photons $\left.\mathrm{m}^{-2} \mathrm{~s}^{-1}\right) / 12 \mathrm{~h}$ dark cycle. Cell concentration was determined by measuring the chlorophyll $a$ concentration (Meyer et al., 2016) according to the methanol extraction protocol (Tanabe et al., 2015).

\section{Phylogenetic Analyses}

Multilocus sequence typing (MLST) of $M$. aeruginosa $\mathrm{Sj}$ was performed according to a published protocol (Tanabe et al., 2007, 2009a). MLST data of other strains used in this study have been previously published (Tanabe and Watanabe, 2011), except for the MLST data of several PCC strains that were retrieved from the whole genome data available from GenBank. Phylogenetic analyses of the seven MLST loci of 250 strains (Supplementary Table S2) were performed by neighbor-joining (NJ) and maximum-likelihood (ML) methods using MEGA version 5.2 (Tamura et al., 2011) and RAxML (Stamatakis, 2006), respectively. The NJ tree reconstruction and bootstrap analysis (1 000 resamplings) employed the maximum composite likelihood substitution model with uniform nucleotide substitution rates among sites and lineages. RAxML was run at Cipres Science Gateway (Miller et al., 2010b) under the default settings, except that bootstrap analysis was performed with 1,000 replicates.

Amino acid alignments of proteins encoding each sucrose gene were generated using clustal X ver. 1.81 (Thompson et al., 1997). The manual removal of gaps and ambiguous sites yielded alignments consisting of 791, 227, and 381 amino acids for susA, $s p p A$, and $s p s A$, respectively (alignments are available on request). Methods for phylogenetic reconstruction are the same as those for MLST, except that JTT protein substitution model was used for NJ tree reconstruction, and "protein GAMMA" and protein matrix option "AUTO" were used for RAxML analyses.

\section{Whole Genome Shotgun Analyses}

Samples of $M$. aeruginosa $\mathrm{Sj}$ and NIES-1211 were not axenic. However, Sj and NIES-1211 cells are much larger than the contaminants, so repeated washing with vacuum filtration using a Mixed Cellulose Esters Membrane (pore size $1.2 \mu \mathrm{m}$, Merck Millipore, Carrigtwohill, Ireland) successfully yielded nearly contaminant-free samples. Genomic DNA was extracted from washed $\mathrm{Sj}$ using potassium ethyl xanthogenate (Tillett and Neilan, 2000) and from NIES-1211 cells using NucleoBond ${ }^{\circledR}$ AXG Columns with Buffer set III (MachereyNagel, Düren, Germany). Whole genome shotgun sequencing of a 350 bp paired-end library constructed using a TrueSeq Nano DNA library Prep Kit (Illumina, San Diego, CA) was performed on a HiSeq 2500 system (Illumina). De novo assembly of the contigs was performed using Spades ver. 3.10.1 (Bankevich et al., 2012) and automated annotations were performed using Prokka ver. 1.12 (Seemann, 2014). Contigs of possible contaminants were excluded on the basis of lower coverage (identified by Spades) and a BLAST analysis. The whole genome shotgun datasets of $\mathrm{Sj}$ and NIES-1211 have been deposited in the DNA Database of Japan (DDBJ) under accession nos. BDSG01000000 and BEIV01000000, respectively.

\section{Gene Expression Analyses}

A 1-ml volume of $M$. aeruginosa mid-exponential culture was transferred to a $1.5-\mathrm{ml}$ test tube with or without addition of $10 \mathrm{~g}$ $\mathrm{l}^{-1} \mathrm{NaCl}$. After $24 \mathrm{~h}$ incubation under the same culture condition described in "Growth experiments," cells were harvested by centrifugation at 20,000 $\mathrm{g}$ for $10 \mathrm{~m}$, immediately submerged in liquid $\mathrm{N}_{2}$, and stored at $-80^{\circ} \mathrm{C}$ until RNA extraction. Salt-free experiments were performed as described above except that a mid-exponential culture of $M$. aeruginosa in MA with $10 \mathrm{~g} \mathrm{l}^{-1}$ $\mathrm{NaCl}$ was centrifuged and resuspended in MA with or without $10 \mathrm{~g}^{-1} \mathrm{NaCl}$. RNA extraction was performed using the RNeasy ${ }^{\circledR}$ Plant Miki Kit (Quiagen, Germantown, MD) according to the manufacturer's protocol with the following minor modification: at the initial step, zirconium beads $(0.1 \mathrm{~mm}$ in diameter) were added into the microtube and cells were disrupted using a mini Bead-Beater (Biospec Products, Bartlesville, OK) at 4,200 rpm for 30 s. Residual DNA was dissolved using the RNase-Free DNase Set (Quiagen). Contamination of genomic DNA was checked by $\mathrm{PCR}$ reactions using the primer pair ftsF/ftsR targeting fts $Z$ DNA (Tanabe et al., 2007). cDNA synthesis and RT-qPCR reactions were performed using the One Step SYBR ${ }^{\circledR}$ PrimeScript ${ }^{\mathrm{TM}}$ PLUS RT-PCR kit (Takara, Shiga, Japan) with sucrose gene specific primers (Supplementary Table S3) according to the manufacture's protocol. Transcripts of $r n p B$ were used as a reference (Makower et al., 2015). The primer specificities for RTqPCR reactions were confirmed by melting curve analysis (Ririe et al., 1997). The results of RT-qPCR were assessed using the comparative $\mathrm{C}_{\mathrm{T}}$ method (Schmittgen and Livak, 2008). All RTqPCR analyses were performed using the Applied Biosystems StepOnePlus Real-Time PCR system (Thermo Fisher Scientific, Waltham, MA).

\section{Sucrose Gene Detection and Genotyping}

Detection of three sucrose genes ( $s p p A, s p s A$, and $s u s A)$ was performed using the primer pairs, sppA_1F/1R, spsA_1F/1R, and susA_1F/1R, respectively (Supplementary Table S4). The genome sequencing of $S j$ revealed that these primers did not cover polymorphic sites found between Sj and PCC 7806 strains. Therefore, two new primer pairs, spsA_3F/3R and susA_2F/2R, were used for PCR genotyping of $s p s A$ and $s u s A$. PCR conditions and sequencing methods were the same as those reported for MLST loci (Tanabe et al., 2007) except for the annealing temperatures (Supplementary Table S4).

\section{Genetic Composition Analyses}

Genetic composition analysis of $M$. aeruginosa using clone library analyses was based on $f t s Z$, one of the seven MLST loci (Tanabe et al., 2007). This locus can be used to assign the ftsZ genotype into defined MLST phylogenetic groups (Tanabe and Watanabe, 2011). Environmental DNA was extracted using a FastDNA SPIN kit (MP Biomedicals, Tokyo, Japan). PCR amplification was performed using the high fidelity DNA polymerase Pyrobest ${ }^{\circledR}$ (Takara, Shiga, Japan). Amplified fragments were cloned using the Zero Blunt ${ }^{\circledR}$ TOPO ${ }^{\circledR}$ PCR 


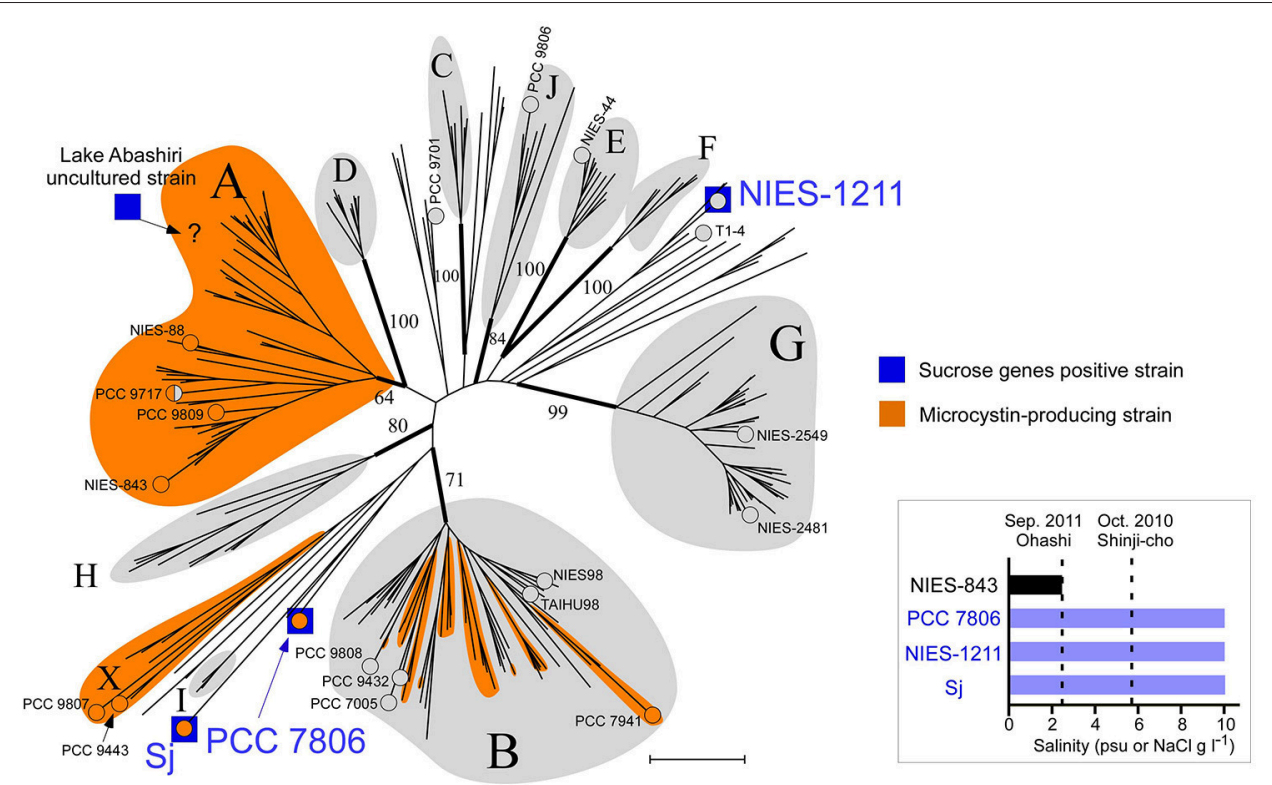

FIGURE 2 | Phylogeny of salt-tolerant M. aeruginosa. A multilocus neighbor-joining (NJ) phylogenetic tree based on seven housekeeping loci (Tanabe et al., 2007). Groups are defined according to a previous report (Tanabe and Watanabe, 2011) with three new designations (groups H, I, and J). Numbers at the selected nodes indicate bootstrap values inferred from RaxML. M. aeruginosa strains for which a whole genome sequence was available are indicated by "o" and the strain name. Strain PCC 9717 is indicated in half-orange color because it has an incomplete microcystin synthetase gene cluster (Humbert et al., 2013). A possible placement of a Lake Abashiri clone (positive for sucrose genes) in group A is indicated with "?." Scale bar, 0.005 substitutions per sites. Inset: Salt tolerance of three sucrose gene-positive strains and one sucrose gene-negative strain. Note that psu (salt concentration determined from conductivity) and $\mathrm{NaCl}$ concentration in MA medium are substantially the same value.

cloning kit (Thermo Fisher Scientific) and $>30 \mathrm{ftsZ}$-positive clones were sequenced. A clone was assigned to a specific group when the sequence was of the same genotype as that assigned by previous MLST (Supplementary Table S2) or located inside the group defined by MLST. Otherwise, the clone was designated "NA." All ftsZ sequence data are available as Supplementary Data S1.

\section{Sucrose Analyses}

Mid- to late-log phase precultures of $\mathrm{Sj}$ were filtrated gently using an Isopore ${ }^{\mathrm{TM}}$ membrane filter (pore size $1.2 \mu \mathrm{m}$, Merck Millipore) to minimize bacterial contamination and possible bacterial sucrose synthesis, and then resuspended at $5 \mathrm{ml} \mathrm{Sj}$ cell suspension to $5.5 \mathrm{ml}$ fresh MA medium with or without $10 \mathrm{~g} \mathrm{l}^{-1} \mathrm{NaCl}$ in $20-\mathrm{ml}$ test tubes. Tubes were incubated in the chamber described above for $24 \mathrm{~h}$. Before sucrose extraction, cultures were again filtrated using the Isopore ${ }^{\mathrm{TM}}$ membrane filter (pore size $1.2 \mu \mathrm{m}$ ) to minimize bacterial contamination. Cells on the filter were resuspended in MA medium. A $300-\mu l$ aliquot of the suspension was used for chlorophyll extraction and measurement, and the remaining suspension was filtered using a Durapore ${ }^{\circledR}$ membrane filter (pore size $0.65 \mu \mathrm{m}$, Merck Millipore). The filter with $\mathrm{Sj}$ cells was soaked in $7 \mathrm{ml}$ of $80 \% \mathrm{MeOH}$ and the supernatant subjected to sucrose extraction (Ehira et al., 2014). Sucrose concentration was measured by high-performance liquid chromatography using a chromatograph equipped with a SUGAR SP0810 column $(8 \times 300 \mathrm{~mm}$; Shodex, Tokyo, Japan $)$ maintained at $80^{\circ} \mathrm{C}$ and a refractive index detector, with deionized water as the eluent at a flow rate of $1 \mathrm{ml} \mathrm{min}^{-1}$ and a sample volume of $20 \mu \mathrm{l}$. Sucrose content was normalized to chlorophyll $a$ concentration as in previous study (Ehira et al., 2014).

\section{Microcystin Analyses}

A 5-ml sample of exponential phase $\mathrm{Sj}$ culture was mixed with $0.25 \mathrm{ml}$ of acetic acid, sonicated for $10 \mathrm{~min}$, and then centrifuged at $3000 \mathrm{rpm}$ for $20 \mathrm{~min}$ (step one). To the pellet, $0.5 \mathrm{ml}$ of methanol was added and the mixture was sonicated and centrifuged (step two). To the combined supernatants from steps one and two, $5 \mathrm{ng}$ of ${ }^{15} \mathrm{~N}$ labeled microcystin variants (microcystin-LR, -RR, -WR, -FR, -YR, and-7 desmethyl LR) was added as surrogates (Sano et al., 2011). The mixture was absorbed onto a HLB 1 cc cartridge (Waters, Milford, MA), washed with 20\% methanol, and finally eluted with $0.5 \mathrm{ml}$ of $90 \%$ methanol. The cartridge was then

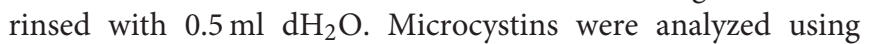
$20 \mu \mathrm{l}$ of the combined eluates by LC-MS/MS (LCMS-8040, Shimadzu, Kyoto, Japan). Each microcystin concentration was determined using calibration curves generated by measuring a series of microcystin standards of the variants listed above. Microcystin content was normalized using chlorophyll a concentration as in a previous study (Meyer et al., 2016). 


\section{RESULTS AND DICUSSION}

\section{Genomic and Physiological Features of Salt-Tolerant Strain $M$. aeruginosa Sj}

First, we analyzed $M$. aeruginosa strain $\mathrm{Sj}$, which has recently been isolated from a Japanese eutrophic brackish water lake, Lake Shinji (Figure 1). Lake Shinji is connected to the sea by a river and another brackish water lake (Lake Nakaumi), and its salinity fluctuates from 0.5 to 8 psu (practical salinity unit) depending on meteorological conditions (Uye et al., 2000). Since 1964, M. aeruginosa blooms have been reported occasionally in the lake. In the year in which $S j$ was isolated, the $M$. aeruginosa bloom was very dense (Supplementary Figure S1), reaching $>89 \mu \mathrm{g}$ chlorophyll $a \mathrm{l}^{-1}$. Genetic composition analyses of $M$. aeruginosa on the basis of $f t s Z$ indicated that the $M$. aeruginosa blooms in 2010 and 2011 were genetically highly homogenous, comprising almost entirely of a single genotype, which was the same as that of $\mathrm{Sj}$ (Figure 1). The salinity of Lake Shinji from which samples were collected for analyzing genetic composition was 2.5-5.8 psu (Supplementary Table S1), markedly higher than the salinity tolerance level of most known M. aeruginosa strains (Otsuka et al., 1999; Tonk et al., 2007). These observations suggest that the $\mathrm{Sj}$ genotype was adapted to high salinity as early as 2010 or 2011. Indeed, strain $\mathrm{Sj}$ showed salt tolerance up to $10 \mathrm{~g}^{-1} \mathrm{NaCl}$, higher than the salinity of the lake when the strain was isolated (Figure 2 and Supplementary Figure S2A). The observed level of salt tolerance is comparable to other salt-tolerant $M$. aeruginosa strains or conspecific cultures (Orr et al., 2004; Tonk et al., 2007). Even higher salt tolerance, up to $17 \mathrm{~g} \mathrm{l}^{-1} \mathrm{NaCl}$, was obtained in previous reports (Robson and Hamilton, 2003; Tonk et al., 2007). The salinity tolerance of $\mathrm{Sj}$ did not exhibit any improvement even when salt-acclimated cells were used as seeds for the growth experiment (Supplementary Figure S2B), suggesting the presence of stable genetic factors conferring the observed level of salt tolerance.

The draft genome sequence of $\mathrm{Sj}$ identified a set of genes $(s p p A, s p s A$, and $s u s A)$ for compatible solute sucrose synthesis (Figure 3A), while none of the genes for other compatible solutes were found in the genome (Supplementary Table S5). Chemical analysis also revealed sucrose accumulation in response to salt (Figure 3B). Consistent with sucrose accumulation as an osmoprotectant mechanism in salt-tolerant cyanobacteria, all three sucrose genes were expressed in $\mathrm{Sj}$, and expression levels were upregulated in response to salt (Figures 3C,D). In contrast, the expression of the sucrose synthase gene sus $A$ was only slightly downregulated at $24 \mathrm{~h}$ after the transfer of $\mathrm{Sj}$ from saline to salt-free media (Figure 3D). This observation is consistent with previous findings that the susA product is involved in sucrose breakdown (Figure 3A) rather than

A

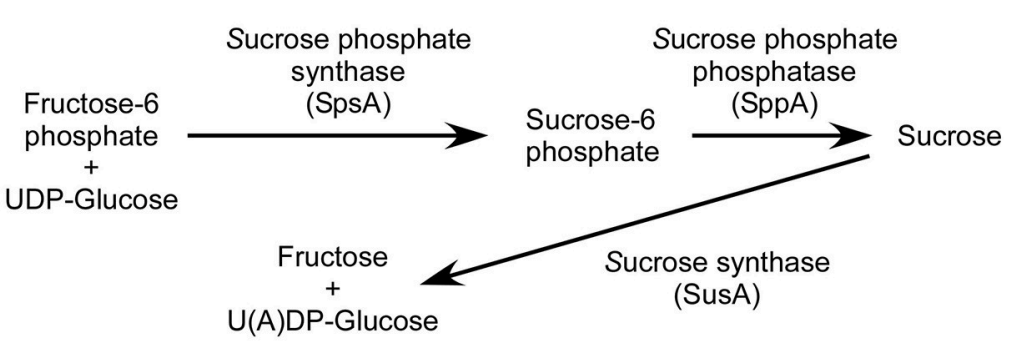

B

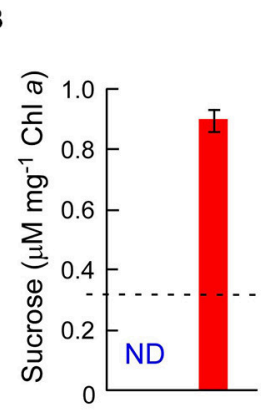

C

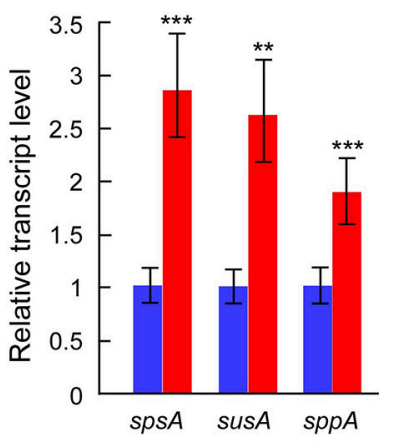

$\mathrm{NaCl} O$ to $0 \mathrm{~g} \mathrm{l}^{-1}$

$\mathrm{NaCl} O$ to $10 \mathrm{~g} \mathrm{l}^{-1}$
D

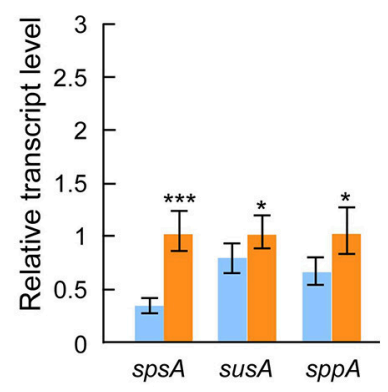

$\mathrm{NaCl} 10$ to $0 \mathrm{~g} \mathrm{l}^{-1}$ $\mathrm{NaCl} 10$ to $10 \mathrm{~g} \mathrm{l}^{-1}$

FIGURE 3 | Chemical analysis of intracellular sucrose and sucrose gene expression analyses. (A), Sucrose gene products and their contributions to sucrose metabolism in $M$. aeruginosa. (B), Sucrose concentrations after $24 \mathrm{~h}$ incubation with or without $10 \mathrm{~g} \mathrm{I}^{-1} \mathrm{NaCl}$. The dotted line indicates the detection limit of liquid chromatography. The sucrose concentration was $>3$ times higher in salt-treated cells than controls. (C), Results of RT-qPCR after the same treatment in (B). (D), Results of RT-qPCR after $24 \mathrm{~h}$ incubation with or without $10 \mathrm{~g} \mathrm{I}^{-1} \mathrm{NaCl}$ using salt-acclimated cells as a seed. Bars indicate $95 \%$ confidence intervals calculated from three biological and three technical replicates (by Student's t, $\mathrm{df}=16$ ). Statistical values are the results of homoscedastic one-tailed $t$-tests of $\Delta \mathrm{C}_{\top}$ means: ${ }^{\star} P<0.05$; ${ }^{\star \star} P<0.01 ;{ }^{\star \star \star} P<0.001$. 
synthesis (Curatti et al., 2002; Hagemann, 2011). It is likely that susA expression is sustained until the intracellular sucrose concentration is reduced to the level of the non-saline condition. On the other hand, the strain NIES-843, which does not possess these sucrose genes (Kaneko et al., 2007), showed much lower salt tolerance (Figure 2 and Supplementary Figure S2C).

A previous study detected another compatible solute, trehalose, in M. aeruginosa PCC 7806 (Meissner et al., 2015), although no homologs of known genes for trehalose synthesis were found in the PCC 7806 genome (Klähn and Hagemann, 2011). Our LC analysis did not detect trehalose in M. aeruginosa $\mathrm{Sj}$, consistent with the absence of genes for trehalose synthesis in the Sj genome (Supplementary Table S5). However, it is possible that the trehalose concentration in $\mathrm{Sj}$ is below the detection limit in this study. The identification of genes responsible for trehalose synthesis in PCC 7806 is critical to clarify this issue.

\section{Genomic and Physiological Features of Salt-Tolerant Strain M. aeruginosa NIES-1211}

Sucrose genes are extremely rare in $M$. aeruginosa. Of 20 $M$. aeruginosa strains for which whole genome sequence data are currently available, only PCC 7806 possesses these sucrose synthesis genes in addition to $\mathrm{Sj}$ (Supplementary Table S2). A comprehensive PCR survey of 210 available strains found none with sucrose genes except NIES-1211 (Supplementary Table S2), which is also of brackish water origin (from Lake Tofutsu, Figure 1). Although the salinity of Lake Tofutsu was not documented at the time of isolation, NIES-1211 showed salt tolerance up to $10 \mathrm{~g} \mathrm{l}^{-1}$ (Figure 2 and Supplementary Figures $\mathrm{S} 2 \mathrm{D}, \mathrm{E})$. We sequenced the whole genome of NIES-1211 to investigate its genomic basis for salt tolerance. The draft genome of NIES-1211 also revealed the presence of the same three sucrose synthesis genes as those of $\mathrm{Sj}$ and PCC 7806 (Figure 4A), while none of the genes for other compatible solutes were found in the genome (Supplementary Table S5). In addition, similar to $\mathrm{Sj}$, the expression levels of these sucrose synthesis genes were upregulated in NIES-1211 by salt (Supplementary Figure S3).

Of note, none of the other genes possibly involved in salt acclimation (Guljamow et al., 2007; Sandrini et al., 2015) are exclusively shared among salt-tolerant $M$. aeruginosa strains (Supplementary Table S5). For example, the genes actM and $p f n M$, which were previously suggested to have a possible involvement in salt tolerance (Guljamow et al., 2007), are absent in $\mathrm{Sj}$ and NIES-1211. These results suggest that sucrose genes are responsible for the salt tolerance of $M$. aeruginosa, and thus allow for M. aeruginosa blooms in brackish water up to 10 psu.
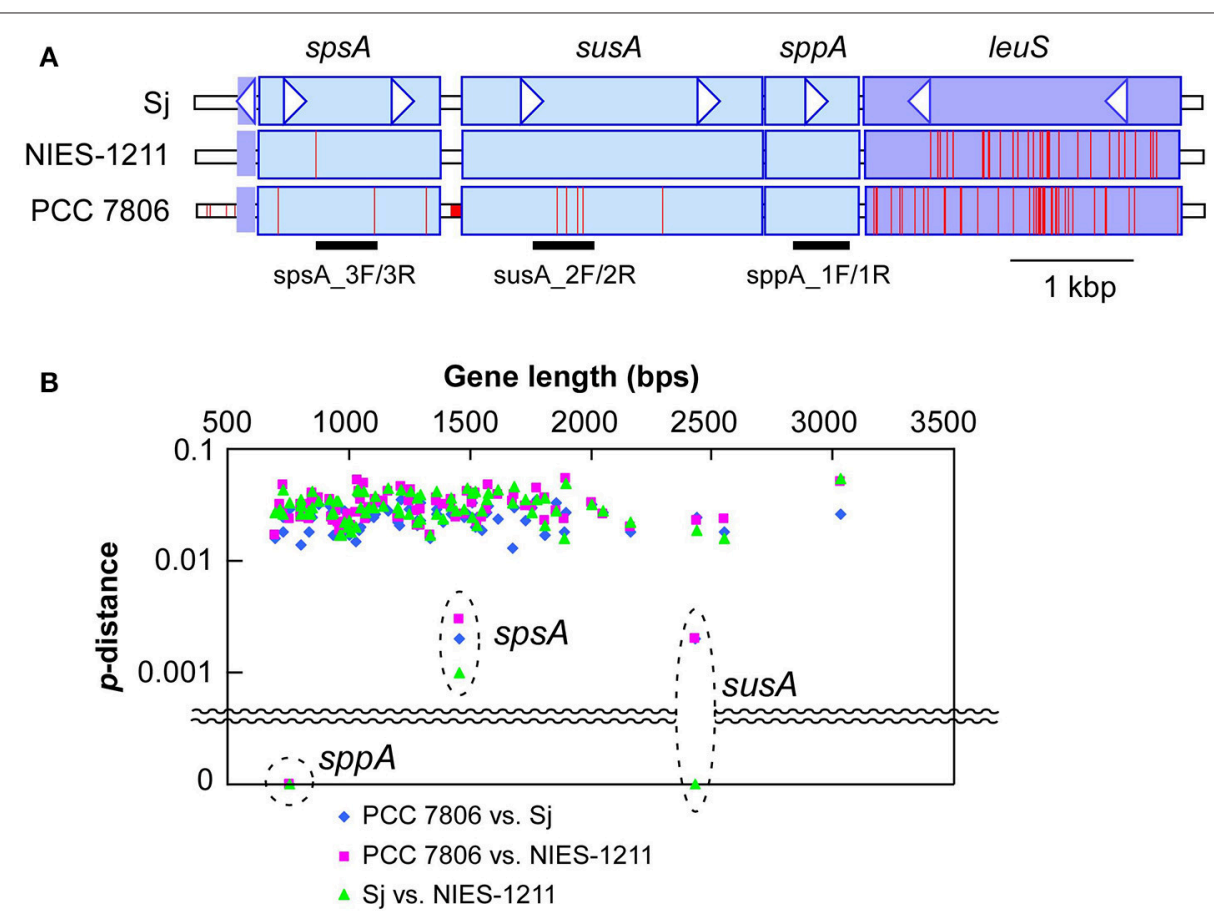

FIGURE 4 | Genetic diversity of sucrose genes. (A), DNA polymorphisms within sucrose genes, and the adjacent leuS locus encoding leucyl-tRNA synthetase. A nucleotide site different from that of $\mathrm{Sj}$ is indicated by a red bar. PCR targets for sucrose genotyping are indicated below the gene diagram. Genes located downstream of leuS showed a level of genetic diversity similar to that shown by leuS (Supplementary Figure S6). (B), Genetic distances of sucrose genes and selected core genome genes (>650 bps in length) including the seven MLST loci (Tanabe et al., 2007) and leuS. The core genome genes included in this analysis are listed in Supplementary Table S6. X-axis indicates nucleotide length of the genes. Y-axis indicates percent nucleotide difference ( $p$-distance) on a log scale. 


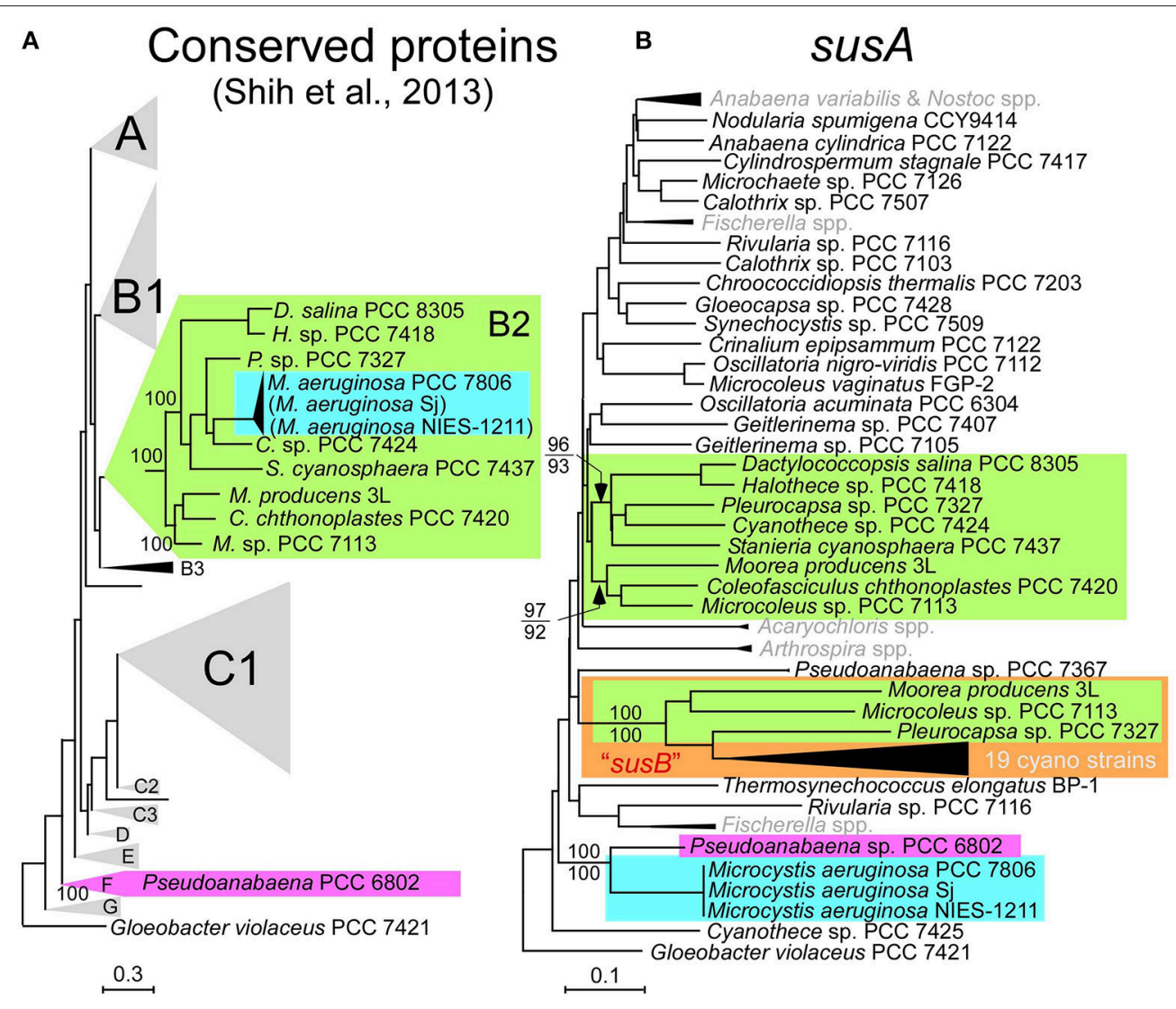

FIGURE 5 | Phylogenetic trees. (A), The phylogenetic tree modified from the conserved protein-based tree with the group designations by Shih et al. (2013). M. aeruginosa Sj and NIES-1211 are not included in the analysis. However, whole-genome blast analyses indicated that Sj and NIES-1211 are most closely related to PCC 7806 in the tree (indicated in parentheses). (B), A NJ phylogenetic tree of susA. Bootstrap values (>70) on the basis of 1000 replicates are indicated at the respective nodes. Numbers in parentheses after the strain name indicate GenBank protein IDs. The color-coding in (B) is according to (A). susB (a homolog of susA; Kolman et al., 2012) is highlighted by the orange box. OTUs in gray in (B) are compressed. Scale bar, substitutions per sites.

\section{Microcystin Content in Response to Salt Stress}

The genome of $\mathrm{Sj}$ contains the complete microcystin synthetase gene cluster ( $m c y A B C D E F G H I J)$, which is responsible for the biosynthesis of microcystins (Tillett et al., 2000), whereas the NIES-1211 genome contains none of the mcy genes. Microcystins are cyclic heptapeptides produced nonribosomally (Tillett et al., 2000) in many M. aeruginosa strains (Figure 2 and Supplementary Table S2). The biological role of microcystins in $M$. aeruginosa is a matter of long-standing debate (Kaplan et al., 2012). Recently, a study reported that microcystins protect cells from oxidative stress by binding and stabilizing proteins, including the RuBisCo enzymes (Zilliges et al., 2011). In this context, whether salt stress affects the level of microcystins in $\mathrm{Sj}$ cells as in the response to oxidative stress is of particular interest for both the ecology and environmental impact of $M$. aeruginosa. To test this, we performed quantitative analyses of microcystins and their gene expressions in Sj. Both microcystin synthetase genes ( $m c y A$ and $m c y E$ ) expressions and chemical microcystin quantification analyses of $\mathrm{Sj}$ indicated that salinity did not significantly affect microcystin concentration per cell throughout the growth period (Supplementary Figure S4). This suggests that microcystins do not respond to salt stress, unlike oxidative stressors, at least in $\mathrm{Sj}$.

\section{Sucrose Gene Acquisition via Recent HGT}

Multilocus phylogenetic analyses indicated that sucrose synthesis is sporadic in $M$. aeruginosa (Figure 2). Given the frequent horizontal gene transfer (HGT) in M. aeruginosa (Guljamow et al., 2007; Tanabe et al., 2009b; Humbert et al., 2013), this rare and patchy distribution of salt tolerance genes is not surprising. Indeed, it was proposed that $M$. aeruginosa likely acquired these sucrose genes by HGT from a distantly related cyanobacterium (Kolman and Salerno, 2016). A comparison of the genome (Shih et al., 2013) and sucrose gene phylogenetic trees of diverse cyanobacteria including $\mathrm{Sj}$ and NIES-1211 also support HGT rather than vertical transmission of sucrose genes from distantly related cyanobacteria (Figure 5). However, the extremely low genetic diversity of sucrose genes among the three salt-tolerant strains is highly unexpected (Figure 4A). Further the core genome genes including the adjacent leuS locus show substantial genetic distance among the three strains regardless 


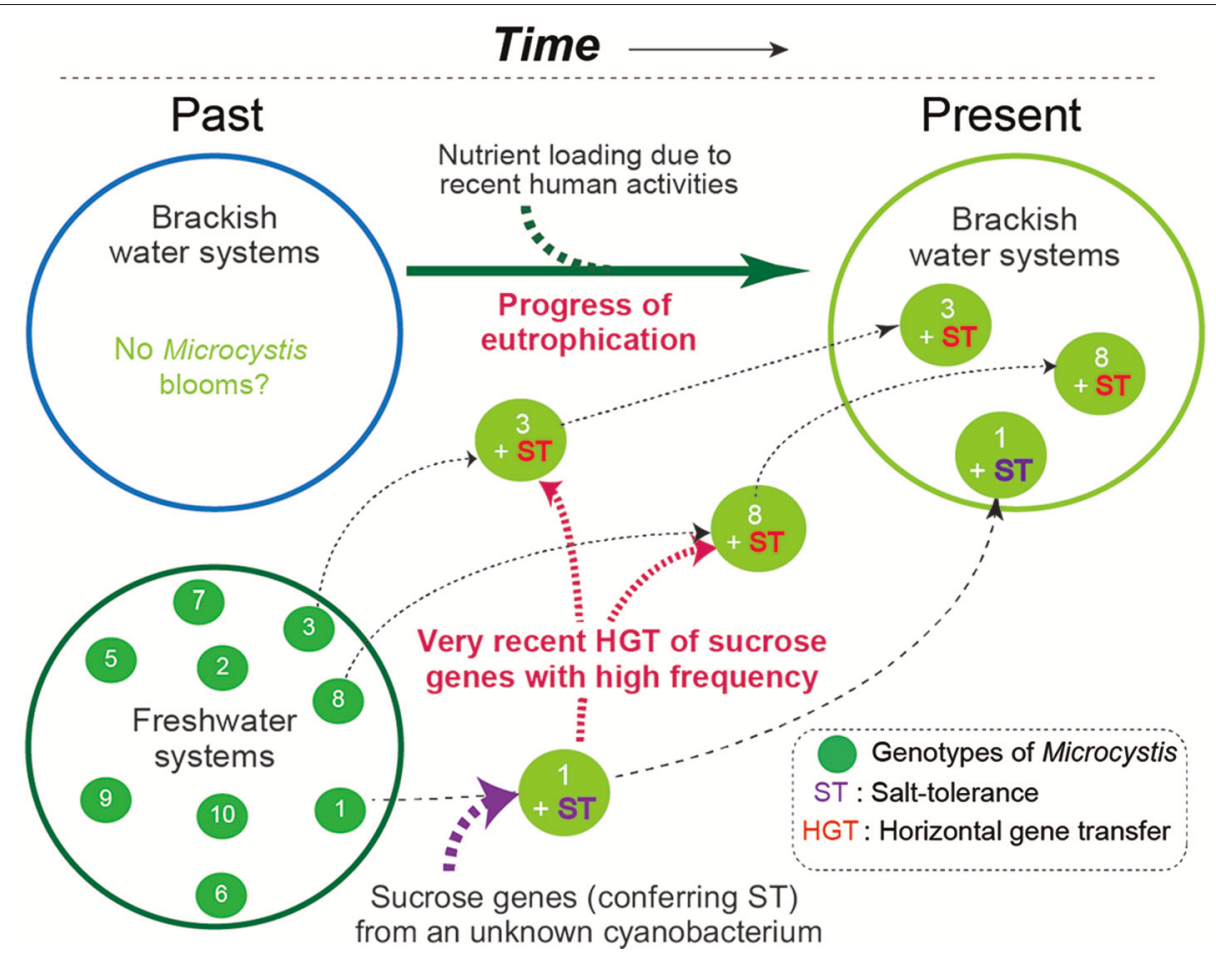

FIGURE 6 | A schematic of the hypothesized $M$. aeruginosa bloom occurrence in Japanese brackish water. In the past, $M$. aeruginosa blooms were restricted to freshwater systems because $M$. aeruginosa is salt-sensitive. At some point in time, one $M$. aeruginosa genotype became salt-tolerant owing to the acquisition of sucrose genes via HGT. Recent eutrophication of brackish water systems caused by human activity has driven the subsequent spread of the sucrose genes in different genotypes of $M$. aeruginosa. As a result, salt-tolerant $M$. aeruginosa have become prevalent and can form blooms in brackish water systems. Note that different numbers indicate different genotypes.

of individual gene length (Figure 4B). For example, the percent divergence of the three sucrose genes, $s p p A, \operatorname{sps} A$, and $s u s A$ between $\mathrm{Sj}$ and NIES-1211 were 0, 0.1, and 0 , respectively; these orders of magnitude are lower than those of other genes in the genome (percent divergence, $>1$ ). This discrepancy can most likely be explained by the very recent introgression of sucrose genes into $M$. aeruginosa and subsequent spread across different strains of $M$. aeruginosa. However, multiple acquisitions from the same source can not be strictly ruled out. The pattern of genetic diversity and the distribution of sucrose genes in the MLST phylogenetic tree suggest either one or two HGTs have occurred within $M$. aeruginosa. It is evident that NIES-1211 has independently acquired sucrose genes via HGT. However, the possiblity of the vertical transmission of sucrose genes in Sj and PCC 7806 is obscured by the extremely low genetic diversity between the two strains. Thus, $\mathrm{Sj}$ and PCC 7806 may have independently acquired sucrose genes via HGT. In susA and $s p p A$ trees (Figure 5B and Supplementary Figure S5A), the sequences of $M$. aeruginosa are most closely related to those of Pseudoanabaena sp. PCC 6802, whereas the sequence of $s p s A$ of $M$. aeruginosa is closely related to those of nitrogen fixing cyanobacteria, including Cyanothece sp. PCC 7425 (Supplementary Figure S5B). This phylogenetic discordance suggests that the sucrose gene cluster in $M$. aeruginosa is a composite of genes from different cyanobacteria. Given the high sequence similarity of the sucrose gene cluster among strains of $M$. aeruginosa, the build-up of the gene cluster would predate the time of its import into $M$. aeruginosa. In any event, the mosaic nature of the gene cluster reflects a complex evolutionary history of the sucrose gene cluster in cyanobacteria

Field surveys of several Japanese brackish water lakes revealed widespread occurrence of the same sucrose gene genotype as $\mathrm{Sj}$ in brackish water with salinity $>1.3$ psu (Supplementary Table S1). The sucrose genes identified in Lake Togo can be ascribed to the presence of $\mathrm{Sj}$ or a similar strain (Figure 1). However, the same sucrose genes were also identified in another brackish water lake, Lake Abashiri, in which Sj has not been observed (Figure 1 and Supplementary Table S1). The prevalence of a single fts $Z$ genotype belonging to group A (Figure 2), which is only distantly related to $\mathrm{Sj}$, might be an evidence of another independent and very recent HGT of sucrose genes. Collectively, these results suggest a very recent expansion of sucrose gene expression and salt tolerance to $M$. aeruginosa in Japanese brackish water environments (Figure 6).

\section{Ecological and Evolutionary Implication}

It is currently unclear why the observed sucrose gene HGT among $M$. aeruginosa has such a short evolutionary history. One hypothesis is that eutrophication of brackish water is a 
prerequisite for the emergence of salt-tolerant $M$. aeruginosa and its invasion from fresh water. Increasing nutrient loading by human activity around coastal areas including lagoons may be the driving force for the recent emergence of salt tolerance in $M$. aeruginosa via HGT. In this scenario, the salt-tolerant $M$. aeruginosa strains identified in this study represent new and potentially stable and long-lasting ecotypes (Cohan, 2002). Another possibility is that the emergence of salt-tolerant $M$. aeruginosa strains in brackish water is transient. In this scenario, while recurrent HGTs of sucrose genes would give rise to salt-tolerant $M$. aeruginosa under favorable salinity conditions, salt tolerance is adaptive in any one place for a very short time owing to salinity fluctuation, such that this new ecotype would immediately become extinct, as reflected in the "species-less model" (Cohan, 2011). We favor the former possibility, however, because $M$. aeruginosa blooms are considered relatively recent phenomena in response to anthropogenic nitrogen loading from agricultural, domestic, and industrial effluents (Harke et al., 2016). In fact, a stable isotope study suggested that the eutrophication in Lake Shinji began in the 1940's (Yamamuro and Kanai, 2005). Nutrient-rich brackish water would favor the mass proliferation of non- $\mathrm{N}_{2}$ fixing cyanobacteria like $M$. aeruginosa with salt tolerance rather than other salt-tolerant $\mathrm{N}_{2}$-fixer species (Harke et al., 2016). In either case, these salt-tolerant $M$. aeruginosa genotypes appear to have been generated very recently.

\section{CONCLUSIONS}

Our data clearly shows that at least a few instances of $M$. aeruginosa bloom in brackish water were caused by salttolerant genotypes harboring sucrose genes. We concluded that transfer of sucrose genes among $M$. aeruginosa is an occurrence with a short evolutionary history; however, the possibility of independent introgression into each strain from unknown vectors (e.g., cyanophages) harboring the same genes cannot be ruled out. We hypothesize that the recent HGT coincided with recent anthropogenic eutrophication in brackish water bodies.

\section{REFERENCES}

Bankevich, A., Nurk, S., Antipov, D., Gurevich, A. A., Dvorkin, M., Kulikov, A. S., et al. (2012). SPAdes: a new genome assembly algorithm and its applications to single-cell sequencing. J. Comput. Biol. 19, 455-477. doi: $10.1089 / \mathrm{cmb} .2012 .0021$

Beasley, V. R., Cook, W. O., Dahlem, A. M., Hooser, S. B., Lovell, R. A., and Valentine, W. M. (1989). Algae intoxication in livestock and waterfowl. Food Anim. Pract. 5, 345-361. doi: 10.1016/S0749-0720(15)30980-4

Cohan, F. M. (2002). What are bacterial species? Annu. Rev. Microbiol. 56, 457-487. doi: 10.1146/annurev.micro.56.012302.160634

Cohan, F. M. (2011). "Are species cohesive? - A view from bacteriology," in Population Genetics of Bacteria: A Tribute to Thomas S Whittam, eds S. T. Walk and P. C. H. Feng (Washington, DC: ASM press), 43-65.

Curatti, L., Flores, E., and Salerno, G. (2002). Sucrose is involved in the diazotrophic metabolism of the heterocyst-forming cyanobacterium Anabaena sp. FEBS Lett. 513, 175-178. doi: 10.1016/S0014-5793(02)0 2283-4
Further investigations on the origin of sucrose genes in $M$. aeruginosa and worldwide field surveys for identification of other salt-tolerant genotypes would help clarify how the rapid evolution of salt-resistance occurred in this ubiquitous toxinproducing cyanobacterial species.

\section{AUTHOR CONTRIBUTIONS}

YT designed the research, YT and YH collected samples, YT performed growth experiments, DNA and gene expression analyses, whole genome analyses, and phylogenetic analyses, YT, KT, and MW performed sucrose analyses, TS performed microcystin analyses, and YT, YH, TS, and KT wrote the paper. All authors read and approved the final manuscript.

\section{FUNDING}

This work was financially supported by JSPS KAKENHI Grant Numbers 15K07523 and 16H02943, and by the Global Environment Research Fund (D-0905) of the Ministry of the Environment, Japan.

\section{ACKNOWLEDGMENTS}

We thank Hidenobu Kunii for providing photos of Microcystis bloom in Lake Shinji, Motohide Ioki, and Kohei Yoneda for technical advice for RNA experiments, Haruyo Yamaguchi, and Yohei Shimura for helpful advice regarding genome DNA extraction and NGS, Masanobu Kawachi and NIESculture collection for providing NIES-843 and NIES-1211, Kako Ohbayashi for helpful comments, and Takafumi Kataoka for helping us collecting brackish water samples.

\section{SUPPLEMENTARY MATERIAL}

The Supplementary Material for this article can be found online at: https://www.frontiersin.org/articles/10.3389/fmicb. 2018.01150/full\#supplementary-material 
Humbert, J. F., Barbe, V., Latifi, A., Gugger, M., Calteau, A., Coursin, T., et al. (2013). A tribute to disorder in the genome of the bloom-forming freshwater cyanobacterium Microcystis aeruginosa. PLoS ONE 8:e70747. doi: 10.1371/journal.pone.0070747

Jochimsen, E. M., Carmichael, W. W., An, J. S., Cardo, D. M., Cookson, S. T., Holmes, C. E., et al. (1998). Liver failure and death after exposure to microcystins at a hemodialysis center in Brazil. New Engl. J. Med. 338, 873-878. doi: 10.1056/NEJM199803263381304

Kaneko, T., Nakajima, N., Okamoto, S., Suzuki, I., Tanabe, Y., Tamaoki, M., et al. (2007). Complete genomic structure of the bloom-forming toxic cyanobacterium Microcystis aeruginosa NIES-843. DNA Res. 6, 247-256. doi: 10.1093/dnares/dsm026

Kaplan, A., Harel, M., Kaplan-Levy, R. N., Hadas, O., Sukenik, A., and Dittmann, E. (2012). The languages spoken in the water body (or the biological role of cyanobacterial toxins). Front. Microbiol. 3:138. doi: 10.3389/fmicb.2012.00138

Kasai, F., Kawachi, M., Erata, M., and Watanabe, M. M. (2004). NIES-Collection, List of Strains, Microalgae and Protozoa, 7th Edn. Tsukuba: National Institute for Environmental Studies.

Klähn, S., and Hagemann, M. (2011). Compatible solute biosynthesis in cyanobacteria. Environ. Microbiol. 13, 551-562. doi: 10.1111/j.1462-2920.2010.02366.x

Kolman, M. A., and Salerno, G. L. (2016). Sucrose in bloom-forming cyanobacteria: loss and gain of genes involved in its biosynthesis. Environ. Microbiol. 18, 439-449. doi: 10.1111/1462-2920.13071

Kolman, M. A., Torres, L. L., Martin, M. L., and Salerno, G. L. (2012). Sucrose synthase in unicellular cyanobacteria and its relationship with salt and hypoxic stress. Planta 235, 955-964. doi: 10.1007/s00425-011-1542-5

Le Rudulier, D., Strom, A. R., Dandekar, A. M., Smith, L. T., and Valentine, R. C. (1984). Molecular biology of osmoregulation. Science 224, 1064-1068. doi: $10.1126 /$ science.224.4653.1064

Makower, A. K., Schuurmans, J. M., Groth, D., Zilliges, Y., Matthijs, H. C., and Dittmann, E. (2015). Transcriptomics-aided dissection of the intracellular and extracellular roles of microcystin in Microcystis aeruginosa PCC 7806. Appl. Environ. Microbiol. 81, 544-554. doi: 10.1128/AEM.02601-14

Meissner, S., Steinhauser, D., and Dittmann, E. (2015). Metabolomic analysis indicates a pivotal role of the hepatotoxin microcystin in high light adaptation of Microcystis. Environ. Microbiol. 17, 1497-1509. doi: 10.1111/1462-2920.12565

Meyer, S., Kehr, J. C., Mainz, A., Dehm, D., Petras, D., Süssmuth, R. D., et al. (2016). Biochemical dissection of the natural diversification of microcystin provides lessons for synthetic biology of NRPS. Cell Chem. Bio. 23, 462-471. doi: 10.1016/j.chembiol.2016.03.011

Miller, M. A., Kudela, R. M., Mekebri, A., Crane, D., Oates, S. C., Tinker, M. T., et al. (2010a). Evidence for a novel marine harmful algal bloom: cyanotoxin (microcystin) transfer from land to sea otters. PLoS ONE 5:e12576. doi: 10.1371/journal.pone.0012576

Miller, M. A., Pfeiffer, W., and Schwartz, T. (2010b). "Creating the CIPRES Science Gateway for inference of large phylogenetic trees" in Proceedings of the Gateway Computing Environments Workshop (GCE) (New Orleans, LA), 1-8.

Orr, P. T., Jones, G. J., and Douglas, G. B. (2004). Response of cultured Microcystis aeruginosa from the Swan River, Australia, to elevated salt concentration and consequences for bloom and toxin management in estuaries. Mar. Freshwater Res. 55, 277-283. doi: 10.1071/MF03164

Otsuka, S., Suda, S., Li, R., Watanabe, M., Oyaizu, H., Matsumoto, S., et al. (1999). Characterization of morphospecies and strains of the genus Microcystis (Cyanobacteria) for a reconsideration of species classification. Phycol. Res. 47, 189-197. doi: 10.1111/j.1440-1835.1999.tb00298.x

Paerl, H. W., and Otten, T. G. (2013). Blooms bite the hand that feeds them. Science 342, 433-434. doi: 10.1126/science. 1245276

Preece, E. P., Hardy, F. J., Moore, B. C., and Bryan, M. (2017). A review of microcystin detections in estuarine and marine waters: environmental implications and human health risk. Harmful Algae 61, 31-45. doi: 10.1016/j.hal.2016.11.006

Ririe, K. M., Rasmussen, R. P., and Wittwer, C. T. (1997). Product differentiation by analysis of DNA melting curves during the polymerase chain reaction. Anal. Biochem. 245, 154-160. doi: 10.1006/abio.1996. 9916
Roberts, M. F. (2005). Organic compatible solutes of halotolerant and halophilic microorganisms. Saline Syst. 1:5. doi: 10.1186/1746-1448-1-5

Robson, B. J., and Hamilton, D. P. (2003). Summer flow event induces a cyanobacterial bloom in a seasonal Western Australian estuary. Mar. Freshwater Res. 54, 139-151. doi: 10.1071/MF02090

Sandrini, G., Huisman, J., and Matthijs, H. C. (2015). Potassium sensitivity differs among strains of the harmful cyanobacterium Microcystis and correlates with the presence of salt tolerance genes. FEMS Microbiol. Lett. 362:fnv121. doi: $10.1093 /$ femsle/fnv121

Sano, T., Takagi, H., Nagano, K., Nishikawa, M., and Kaya, K. (2011). Accurate LC-MS analyses for microcystins using per- ${ }^{15} \mathrm{~N}$-labeled microcystins. Anal. Bioanal. Chem. 399, 2511-2516. doi: 10.1007/s00216-0104639-y

Schmittgen, T. D., and Livak, K. J. (2008). Analyzing real-time PCR data by the comparative CT method. Nat. Prot. 3, 1101-1108. doi: 10.1038/nprot. 2008.73

Seemann, T. (2014). Prokka: rapid prokaryotic genome annotation. Bioinformatics 30, 2068-2069. doi: 10.1093/bioinformatics/btu153

Shih, P. M., Wu, D., Latifi, A., Axen, S. D., Fewer, D. P., Talla, E., et al. (2013). Improving the coverage of the cyanobacterial phylum using diversitydriven genome sequencing. Proc. Natl. Acad. Sci. U.S.A. 110, 1053-1058. doi: $10.1073 /$ pnas. 1217107110

Stamatakis, A. (2006). RAxML-VI-HPC: maximum likelihood-based phylogenetic analyses with thousands of taxa and mixed models. Bioinformatics 22, 2688-2690. doi: 10.1093/bioinformatics/btl446

Tamura, K., Peterson, D., Peterson, N., Stecher, G., Nei, M., and Kumar, S. (2011). MEGA5: molecular evolutionary genetics analysis using maximum likelihood, evolutionary distance, and maximum parsimony methods. Mol. Biol. Evol. 28, 2731-2739. doi: 10.1093/molbev/ msr121

Tanabe, Y., Kasai, F., and Watanabe, M. M. (2007). Multilocus sequence typing (MLST) reveals high genetic diversity and clonal population structure of the toxic cyanobacterium Microcystis aeruginosa. Microbiology 153, 3695-3703. doi: 10.1099/mic.0.2007/010645-0

Tanabe, Y., Kasai, F., and Watanabe, M. M. (2009a). Fine-scale spatial and temporal genetic differentiation of water bloom-forming cyanobacterium Microcystis aeruginosa: revealed by multilocus sequence typing. Environ. Microb. Rep. 1, 575-582. doi: 10.1111/j.1758-2229.2009.00088.x

Tanabe, Y., Okazaki, Y., Yoshida, M., Matsuura, H., Kai, A., Shiratori, T., et al. (2015). A novel alphaproteobacterial ectosymbiont promotes the growth of the hydrocarbon-rich green alga Botryococcus braunii. Sci. Rep. 5:10467. doi: 10.1038/srep10467

Tanabe, Y., Sano, T., Kasai, F., and Watanabe, M. M. (2009b). Recombination, cryptic clades and neutral molecular divergence of the microcystin synthetase ( $m c y)$ genes of toxic cyanobacterium Microcystis aeruginosa. BMC Evol. Biol. 9:115. doi: 10.1186/1471-2148-9-115

Tanabe, Y., and Watanabe, M. M. (2011). Local expansion of a panmictic lineage of water bloom-forming cyanobacterium Microcystis aeruginosa. PLoS ONE 6:e17085. doi: 10.1371/journal.pone.0017085

Thompson, J. D., Gibson, T. J., Plewniak, F., Jeanmougin, F., and Higgins, D. G. (1997). The CLUSTAL_X windows interface: flexible strategies for multiple sequence alignment aided by quality analysis tools. Nucleic Acids Res. 25, 4876-4882. doi: 10.1093/nar/25.24.4876

Tillett, D., Dittmann, E., Erhard, M., von Döhren, H., Börner, T., and Neilan, B. A. (2000). Structural organization of microcystin biosynthesis in Microcystis aeruginosa PCC7806: an integrated peptide-polyketide synthetase system. Chem. Biol. 7, 753-764. doi: 10.1016/S1074-5521(00) 00021-1

Tillett, D., and Neilan, B. A. (2000). Xanthogenate nucleic acid isolation from cultured and environmental cyanobacteria. J. Phycol. 36, 251-258. doi: 10.1046/j.1529-8817.2000.99079.x

Tonk, L., Bosch, K., Visser, P. M., and Huisman, J. (2007). Salt tolerance of the harmful cyanobacterium Microcystis aeruginosa. Aquat. Microb. Ecol. 46, 117-123. doi: 10.3354/ame046117

Uye, S., Shimazu, T., Yamamuro, M., Ishitobi, Y., and Kamiya, H. (2000) Geographical and seasonal variations in mesozooplankton abundance and biomass in relation to environmental parameters in Lake Shinji-Ohashi 
River-Lake Nakaumi brackish-water system, Japan. J. Mar. Syst. 26, 193-207. doi: 10.1016/S0924-7963(00)00054-3

Yamamuro, M., and Kanai, Y. (2005). A 200-year record of natural and anthropogenic changes in water quality from coastal lagoon sediments of Lake Shinji, Japan. Chem. Geol. 218, 51-61. doi: 10.1016/j.chemgeo.2005. 01.021

Zilliges, Y., Kehr, J. C., Meissner, S., Ishida, K., Mikkat, S., Hagemann, M., et al. (2011). The cyanobacterial hepatotoxin microcystin binds to proteins and increases the fitness of Microcystis under oxidative stress conditions. PLOS ONE 6:e17615. doi: 10.1371/journal.pone.00 17615
Conflict of Interest Statement: The authors declare that the research was conducted in the absence of any commercial or financial relationships that could be construed as a potential conflict of interest.

Copyright $(0) 2018$ Tanabe, Hodoki, Sano, Tada and Watanabe. This is an open-access article distributed under the terms of the Creative Commons Attribution License (CC BY). The use, distribution or reproduction in other forums is permitted, provided the original author(s) and the copyright owner are credited and that the original publication in this journal is cited, in accordance with accepted academic practice. No use, distribution or reproduction is permitted which does not comply with these terms. 